\title{
EFFECTS OF THANATOLOGY INTERVENTION PROGRAMME ON KNOWLEDGE AND ATTITUDE OF SECONDARY SCHOOL STUDENTS IN ANAMBRA STATE NIGERIA.
}

\author{
NNAEMEZIE, N. O ${ }^{1}$, PROF. OKAFOR, J.O. ${ }^{2}$, IFEDIORA, U. L. ${ }^{3}$ \\ ARINZE, C.R. ${ }^{4}$. \\ 1,2,3,4 NNAMDI AZIKIWE UNIVERSITY, AWKA, ANAMBRA STATE, NIGERIA \\ (no.nnaemezie@ unizik.edu.ng ${ }^{1}$, oojeromes @ yahoo.com ${ }^{2}$ ulifediora@ unizik.edu.ng, ${ }^{3}$ \\ rcarinze@ unizik.ed.ng. ${ }^{4}$ )
}

Abstract

Introduction: The manner in which a child would cope with dying and death situation would be determined by what the child already know and what knowledge concerning thanatology the child had been exposed to previously. This study was concluded to determine the effect of thanatology intervention programme on knowledge and attitude of secondary school students in Anambra State Nigeria.

Method: The study was delimited to Awka South Local Government Area of Anambra State. Quasi-experimental pre-test, post-test control group design was used on 282 junior and senior secondary school students selected from four secondary schools which included two private schools and two public schools and they were divided into control and experimental groups. The research instrument was a researcher-developed instrument on knowledge and attitude towards thanatology. Mean and standard deviation was used to answer research questions. Analysis of Covariance (ANCOVA) was used to answer the hypotheses at 0.05 level of significance.

Results: The results of the study revealed that there was an increasein the knowledge and attitude of secondary school students after the thanatology intervention programme.

Conclusion: Based on the various findings of the study, it was concluded that thanatology has great effect on the students' knowledge and attitude. Furthermore, it is recommended that thanatology should be taught both informally and formally to help remove or control the fear of dying and death in them. 


\section{Introduction}

Death is a fascinating subject to many children as shown when they lost their pets, class mates, friends and even their teachers. These occurrencessometimes raise a lot of curiosity and questioning and the answers given to them by the mature adults would go a long way to determine how they would cope with such situation. For children to be able to handle their own death and the death of others around them there is need for them to be exposed to death and dying education.

Therefore, dying and death education which is also known as thanatology is the study of death and dying and also the psychological mechanisms of dealing with them (Elisabeth Kubler, 2017). Also according to Duane (2020) Thanatology is the study of death and dying; it deals with the feelings and other psychological phenomena that are encountered by the person who is dying and people who takes care of the dying patient. Children are sometimes part of the lives of dying patients, example children taking care of their elderly parents and sometimes living with such people or children staying in a rural environment where burials and other burial activities take place. By providing children with death and dying education it could become part of them in their everyday lives. And by including death and dying education in their school curriculum, children could also extend their knowledge of thanatology to their relatives such as families and close friends in order to reduce their fear of death and also make good decision with regards to death situation (The Conversation, 2018).

According to Encyclopaedia.Com (220), the term thanatology are educational activities of various forms with experience related to death and embraces such core topics as meanings and attitudes toward death, processes of dying and bereavement, and care for people affected by death. Thanatology also provides these children with basic knowledge on death issues. Death and dying education could be provided to a child both informally and formally. Formally, teachers could use the death of a teacher in the school or death of a class mate as a situation to educate children on death and dying. Also informally, parents could use the death of parents, sibling, and pets as a teaching moment to educate children at home instead of shying away from death education and seeing it as a taboo. The study was brought about due to the inevitable nature of death. Since death cannot be avoided and children need to cope with their own death and the death of others and also to clear and show the difference between death experiences in the movies and television shows and the real life experience with death and dying. Therefore, this study was designed to determine the effects of thanatology intervention programme on knowledge and attitude of secondary school students in Anambra State Nigeria.

\section{Method}

The design for the study was a quasi-experimental pre-test, post-test with control group design. A quasi-experiment is an empirical intervention study used to estimate the causal impact of an intervention on target population without random assignment. Awka South Local Government Area of Anambra State Nigeria was used. A total of 282 junior and senior secondary school students were used drawn from the total population of students in Awka South L.G.A. The sample of 282 students was gotten using a multi-stage sampling procedure to get two public schools and two private schools whereby one of each of he private and public schools formed experimental group and control group schools. The instrument for data collection was a Thanatology Knowledge Test and Attitude Questionnaire (TKTAQ). The instrument was a 
researcher developed instrument. The instrument was validated by experts in thanatology and reliability done using Kudder-Richard ( $\mathrm{K}-\mathrm{R} 20)$ for knowledge test and Cronbach Alpha's Internal Consistency Measure for attitude items and the reliability co-efficient were 0.80 for knowledge test and 0.925 for attitude items.

\section{Intervention Procedure for Experimental and Control Group}

The intervention programme on thanatology took place for 12 weeks in each of the schools. It was fixed alongside their school time table in order not to create bias in the mind of the students. In order to determine thestudents' knowledge and attitude before the programme a pre-test examination was done and after the 12 weeks, a post-test examination was also given to the students to determine if there was any effect of the students' knowledge and attitude. Statistical package for social science (SPSS) was used for data analyses. Mean and standard deviation was used to answer the research questions. The differences between the pre-test mean and the posttest mean was regarded as the mean differences scores. Analysis of Covariance (ANCOVA) was used to test all the hypotheses at 0.05 level of significance. When the pre-test score is higher than the post-test score, there is a mean loss but when the post-test score is higher than the pre-test score, then there is a mean gain.

\section{Research Questions}

1) What are the mean knowledge scores of secondary school students in both experimental and control groups before and after thanatology intervention programme?

2) What are the mean knowledge scores of public and private secondary school students in both experimental and control groups before and after thanatology intervention programme?

3) What are the mean attitude scores of secondary school students in both experimental and control groups before and after thanatology intervention programme?

4) What are the mean attitude scores of public and private secondary school students in both experimental and control groups before and after thanatology intervention programme?

\section{Hypotheses}

1) The effects of thanatology intervention programme on the health knowledge scores of secondary school students in Anambra State Nigeria will not differ significantly using their post mean scores.

2) The effects of thanatology intervention programme on the health knowledgescores of private and public secondary school students in Anambra State Nigeria will not differ significantly using their post mean scores.

3) The effects of thanatology intervention programme on the health attitude scores of secondary school students in Anambra State Nigeria will not differ significantly using their post mean scores.

4) The effects of thanatology intervention programme on the health attitude scores of private and public secondary school students in Anambra State Nigeria will not differ significantly using their post mean scores. 


\section{Presentation and Analysis of Data}

Research Question 1: What are the mean knowledge scores of secondary school students in both experimental and control groups before and after thanatology intervention programme?

Table 1: Pre-test and Post-Test Mean Knowledge Scores of Students in Experimental and Control Groups Before and After Thanatology Intervention Programme $(n=282)$.

\begin{tabular}{|c|c|c|c|c|c|c|c|c|}
\hline Source of Variation & $\mathbf{n}$ & $\begin{array}{c}\text { Pretest } \\
\text { X }\end{array}$ & & SD & $\begin{array}{l}\text { Posttest } \\
\text { X }\end{array}$ & & $\begin{array}{l}\text { SD } \quad X \\
\text { Difference }\end{array}$ & - \\
\hline Experimental Group & 163 & 19.04 & 3.42 & 20.02 & 3.16 & 0.98 & & \\
\hline Control Group & 119 & 19.78 & 3.03 & 19.34 & 3.51 & -0.44 & & \\
\hline
\end{tabular}

Table 1 reveals the pre-test and post-test mean knowledge scores of secondary school students in experimental group to be 19.04 and 20.02 with a gained mean of 0.98 while the control group had 19.78, 19.34 and -0.44 as mean pre-test, post-test and mean loss scores respectively. This shows that the experimental group had better mean knowledge score than their counterparts control group. The standard deviation for the experimental group was close to the central mean with the value of 3.16 .

Research Question 2: What are the mean knowledge scores of public and private secondary school students in both experimental and control groups before and after thanatology intervention programme?

Table 2: Pre-test and Post-test Mean Knowledge Scores of Public and Private Students in Experimental and Control Groups Before and After Thanatology Intervention Programme $(\mathrm{n}=\mathbf{2 8 2})$.

\begin{tabular}{|c|c|c|c|c|c|c|c|}
\hline Source of Variation & $\begin{array}{l}\text { School } \\
\text { Type }\end{array}$ & $\mathbf{n}$ & $\underset{\bar{X}}{\text { Pretest }}$ & SD & $\underset{X}{\text { Posttest }}$ & $\begin{array}{c}\text { SD } \\
\text { Diff }\end{array}$ & ence \\
\hline \multirow[t]{2}{*}{ Experimental Group } & Public & 105 & 18.56 & 3.69 & 19.83 & 3.42 & 1.27 \\
\hline & Private & 58 & 19.90 & 2.67 & 21.74 & 2.15 & 1.84 \\
\hline \multirow[t]{2}{*}{ Control Group } & Public & 69 & 19.52 & 2.88 & 18.75 & 3.81 & -0.77 \\
\hline & Private & 50 & 20.14 & 3.23 & 20.16 & 2.90 & 0.02 \\
\hline
\end{tabular}

Table 2 shows the pre-test and post-test mean knowledge scores of 18.56 and 19.83 for public and 19.90 and 21.74 for private secondary students in experimental group. The students in public schools had a gained mean knowledge score of 1.27 while the private schools had 1.84. Also, public school students in the control group had 19.54, 18.75 and -0.77 as their pre-test, post-test and mean loss knowledge score respectively while the private schools had 20.14, 20.16 and 0.02 as pre-test, post-test and gained mean knowledge scores respectively. This shows that public and 
private school students in the experimental group had better mean knowledge scores. The standard deviations of the public and private schools of the experimental group were close to the central mean with the value of 3.42 and 2.15 respectively.

Research Question 3: What are the mean attitude scores of secondary school students in both experimental and control groups before and after thanatology intervention programme?

Table 3: Pre-test and Post-test Mean Attitude Scores of Students in Experimental and Control Groups Before and After Thanatology Intervention Programme $(n=282)$.

\begin{tabular}{llccccccc}
\hline Source of Variation & $\mathbf{n}$ & $\begin{array}{c}\text { Pretest } \\
\mathbf{X}\end{array}$ & SD & \multicolumn{2}{c}{$\begin{array}{l}\text { Posttest } \\
\mathbf{X}\end{array}$} & SD & $\begin{array}{l}\text { X } \\
\text { Difference }\end{array}$ & - \\
\hline Experimental Group & 16388.00 & 10.53 & 92.76 & 10.99 & 4.76 \\
Control Group & 119 & 88.98 & 12.10 & 89.51 & 12.16 & 0.53 \\
\hline
\end{tabular}

The result in table 3 reveals the pre-test and post-test mean attitude scores of secondary school students in experimental group to be 88.00 and 92.76 with a gained mean of 4.76 while the control group had $88.98,89.51$ and 0.53 as mean pre-test, post-test and mean gained scores respectively. Both the mean post-test score and gained mean attitude score of students in experimental group were better than that of the control group. The standard deviation of the experimental group with the value of 10.99 was close to the central mean than that of the control group.

Research Question 4: What are the mean attitude scores of public and private secondary school students in both experimental and control groups before and after thanatology intervention programme?

Table 4: Pre-test and Post-test Mean Attitude Scores of Public and Private Secondary School Students in Experimental and Control Groups Before and After Thanatology Intervention Programme $(n=282)$.

\begin{tabular}{|c|c|c|c|c|c|c|c|}
\hline Source of Variation & $\begin{array}{l}\text { School } \\
\text { Type }\end{array}$ & $\bar{n}$ & $\begin{array}{l}\text { Pretest } \\
\overline{\mathrm{X}}\end{array}$ & SD & $\begin{array}{c}\text { Posttest } \\
\bar{X}\end{array}$ & SD & $\underset{\text { Difference }}{\overline{\mathrm{X}}}$ \\
\hline \multirow[t]{2}{*}{ Experimental Group } & Public & 105 & 89.10 & 10.62 & 94.59 & 10.25 & 5.49 \\
\hline & Private & 58 & 86.00 & 10.14 & 89.45 & 11.60 & 3.45 \\
\hline \multirow[t]{2}{*}{ Control Group } & Public & 69 & 88.94 & 13.18 & 91.70 & 11.66 & 2.76 \\
\hline & Private & 50 & 89.02 & 10.55 & 86.50 & 12.31 & -2.52 \\
\hline
\end{tabular}

Table 4 shows the pre-test and post-test mean attitude scores of 89.10 and 94.59 for public and 86.00 and 89.45 for private secondary school students in experimental group. The students in public schools had a gained mean score of 5.49 while their counterparts in private schools had 
3.45. Also, public school students in control group had $88.94,91.70$ and 2.76 as their pre-test, post-test and gained mean scores respectively while their counterparts in private school had $89.02,86.50$ and -2.52 as pre-test, post-test and mean loss scores respectively. This shows that the public and private school students in the experimental group had better attitude towards thanatology than the public and private students in the control group. Also the standard deviations of public and private school students in the experimental group were closer to the central mean with variance of 10.25 and 11.60 than that of the control group.

\section{Hypotheses Testing}

Hypothesis 1: The effects of thanatology intervention programme on the health knowledge scores of secondary school students in Anambra State Nigeria will not differ significantly using their post mean scores.

Table 5: Summary of ANCOVA of the Mean Knowledge Scores of Students in Both Experimental and Control Groups Before and After Thanatology Intervention Programme $(\mathbf{n}=\mathbf{2 8 2})$.

\begin{tabular}{|c|c|c|c|c|c|c|}
\hline Source & SS & $d f$ & MS & Fp.value & & \\
\hline Corrected Model & 1500.176 & & 2 & 750.088 & 125.560 & .000 \\
\hline Intercept & 333.384 & & 1 & 333.384 & 55.806 & .000 \\
\hline Pretest & 1406.875 & & 1 & 1406.875 & 235.501 & .000 \\
\hline Group & 190.885 & & 1 & 190.885 & 31.953 & .000 \\
\hline Error & \multicolumn{2}{|c|}{1666.736} & 279 & 5.974 & & \\
\hline Total & 7.000 & 282 & & & & \\
\hline
\end{tabular}

Table 5 shows that there was a significant difference between the mean knowledge scores of secondary school students in both experimental and control groups after thanatology intervention programme. $\mathrm{F},(1,279)=31.953, \mathrm{P}<0.05$. The null hypothesis of no significant difference between the two groups was therefore rejected.

Hypothesis 2: The effects of thanatology intervention programme on the health knowledge scores of private and public secondary school students in Anambra State Nigeria will not differ significantly using their post mean scores. 
Table 6: Summary of ANCOVA of the Mean Knowledge Scores of Public and Private Secondary School Students in Both Experimental and Control Groups Before and after Thanatology Intervention Programme $(n=282)$.

\begin{tabular}{lrrrrr}
\hline Source & \multicolumn{1}{c}{ SS } & \multicolumn{3}{c}{ MS } & Fp.value \\
\hline Corrected Model & 1365.171 & 2 & 682.586 & 105.699 & .000 \\
Intercept & 458.285 & 1 & 458.285 & 70.966 & .000 \\
Pretest & 1193.090 & 1 & 1193.090 & 184.750 & .000 \\
School Type & 55.881 & 1 & 55.881 & 8.653 & .004 \\
Error & 1801.740 & 279 & 6.456 & & \\
Total & 116167.000 & 282 & & & \\
\hline
\end{tabular}

In table 6 the analysis shows that there was a significant difference between the mean knowledge scores of public and private secondary school students in both experimental and control groups after thanatology intervention programme. F, $(1,279)=8.653, \mathrm{P}<0.05$. The null hypothesis of no significant difference between the two groups was therefore rejected.

Hypothesis 3: The effects of thanatology intervention programme on the health attitude scores of secondary school students in Anambra State Nigeria will not differ significantly using their post mean scores.

Table 7: Summary of ANCOVA of the Mean Attitude Scores of Students in Both Experimental and Control Groups Before and After Thanatology Intervention Programme $(\mathbf{n}=282)$.

\begin{tabular}{lrrrrr}
\hline Source & \multicolumn{1}{c}{ SS } & MS & Fp.value & & \\
\hline Corrected Model & 6894.726 & 2 & 3447.363 & 31.159 & .000 \\
Intercept & 12955.116 & 1 & 12955.116 & 117.093 & .000 \\
Pretest & 6169.033 & 1 & 6169.033 & 55.758 & .000 \\
Group & 919.458 & 1 & 919.458 & 8.310 & .004 \\
Error & 30868.366 & 279 & 110.639 & & \\
Total & 2393068.000 & 282 & & & \\
\hline
\end{tabular}


Table 7 shows that there was a significant difference between the mean attitude scores of secondary school students in experimental and control groups after thanatology intervention programme. $\mathrm{F},(1,279)=8.310, p<0.05$. The null hypothesis of no significant difference between the two groups was therefore rejected.

Hypothesis 4: The effects of thanatology intervention programme on the health attitude scores of private and public secondary school students in Anambra State Nigeria will not differ significantly using their post mean scores.

Table 8: Summary of ANCOVA of the Mean Attitude Scores of Private and Public Students in Both Experimental and Control Groups Before and After Thanatology Intervention Programme $(n=282)$.

\begin{tabular}{|c|c|c|c|c|c|}
\hline Source & SS $\quad d f$ & $\overline{M S}$ & Fp.value & & \\
\hline Corrected Model & 7443.047 & 2 & 3721.523 & 34.245 & .000 \\
\hline Intercept & 13788.474 & 1 & 13788.474 & 126.879 & .000 \\
\hline Pretest & 5529.130 & 1 & 5529.130 & 50.878 & .000 \\
\hline School Type & 1467.779 & 1 & 1467.779 & 13.506 & .000 \\
\hline Error & 30320.046 & 279 & 108.674 & & \\
\hline Total & 68.000 & & & & \\
\hline
\end{tabular}

In Table 8 the analysis shows that there was a significant difference between the mean attitude scores of public and private secondary school students in both experimental and control groups after thanatology intervention programme. $\mathrm{F},(1,279)=13,506, p<0.05$. The null hypothesis of no significant difference between the two groups was therefore rejected.

\section{Discussion}

The experimental group had improved mean knowledge score than their counterpart in the control group after the thanatology intervention programme. The finding of the study also showed that thanatology intervention programme had positive effect on the knowledge of the students as evidenced by the mean gained scores of the students in the experimental group after the thanatology intervention programme. The increase in knowledge was as a result of their being exposed to thanatology programme. The study was supported by the work of Mark and Karem (2006) which showed that after such programme, the students who were used for the study had a big increase in knowledge. The study also disagreed with Thea, Victor and Colette (1998) which stated that there was no increase in knowledge after the intervention programme.

The finding of the study also showed that the public and private schools in the experimental group had better mean knowledge scores after the intervention programme on thanatology better than their counterparts in the control group. Students in the private schools gained more knowledge than their counterparts who were in public schools. This is because the academic standards of students in the private schools are more organized to be compared to the academic standard of public schools. Also the null hypothesis of no significant difference between the 
mean knowledge scores of public and private secondary schools students in both experimental and control groups after the intervention programme was therefore rejected.

The experimental group had improved mean attitude scores than their counterparts in the control group after the interventionprogramme on thanatology. The null hypothesis of no significant difference between the mean attitude scores of secondary school students in experimental and control groups before and after thanatology intervention programme was therefore rejected.

The public and private schools in the experimental group had better mean attitude scores after intervention programme on thanatology than their counterparts in control group. The students in the public schools had a higher mean gained attitude score than their counterparts who were in the private schools. The null hypothesis of no significant difference between the mean attitude scores of public and private secondary school students in both experimental and control groups before and after thanatology intervention programme was therefore rejected.

\section{Conclusion}

Based on the findings and results of the study, it was concluded that thanatology intervention programme has been proved effective in educating students on death and dying issue. The finding of the study also indicated that after the intervention programme, there was a positive effect on the students' knowledge of thanatology as well as their attitude. Also for the students in the control group, they had a mean loss. This was because of lack of not being exposed to the thanatology intervention programme which greatly affected their knowledge as well as their attitude towards thanatology.

\section{Recommendation}

The following recommendations were made based on the finding of this study:

1) Health education should also stress the issue related to dying and death as it is also part of life and also inevitable.

2) Thanatology should be taught both formally and informally to every child using teachable moments at home as well as at school to educate children the more in order to remove fear of death in them.

3) Thanatology programme should be taught in all schools. This could help in the reduction of suicide attempt among adolescents in our society. 


\section{References}

Duane Cloud. (2020). Death and dying. Retrieved from https://study.com/academy/lesson/ thanatology-definition-lesson.html.

Elisabeth Kubler-Ross. (2012). Thanatology. Retrieved from https://www.britannica.com/ science /thanatology.

Encyclopaedia.Com. (2018). Death Education. Retrieved from https://www.encyclopaedia.com/ social-science/encyclopaedia-almanac-transcripts-and-maps/death-education.

The Conversation. (2018). Death: why children should be taught about it in school. Retrieved from https://theconversation.com/death-why-children-should-be-taught-about-it-inschool-99541. 